\title{
A VERTICALIZAÇÃO DO BAIRRO COLÔNIA DO MARÇAL: EXPANSÃO URBANA E O MERCADO IMOBILIÁRIO EM SÃO JOÃO DEL-REI (MG)
}

\section{THE VERTICALIZATION OF THE NEIGHBORHOOD COLÔNIA DO MARÇAL: URBAN EXPANSION AND THE REAL ESTATE MARKET IN SÃO JOÃO DEL-REI (MG)}

\author{
Jeziel Silveira SILVA ${ }^{1}$ \\ Denise Leite MARQUES ${ }^{2}$ \\ Marcio TOLEDO $^{3}$
}

\begin{abstract}
Resumo: Desde o começo dos anos 2000, o número de moradias verticais na paisagem urbana, em escala global, vem aumentando. Este artigo tem como objetivo, analisar o surgimento e o crescimento das construções verticais no município de São João del-Rei (MG), através de sua ampliação no sentido norte-nordeste da cidade, no bairro Colônia do Marçal. Destacamos como objetivos específicos a análise da ação dos agentes produtores do espaço urbano (proprietários de terra e incorporadores imobiliários) diante desse fenômeno, além buscar compreender o aumento da procura por esse tipo de moradia. Diante disso, para a execução da pesquisa, foram realizados levantamentos bibliográficos e aplicados questionários junto a população residente nos prédios e aos agentes imobiliários, o que possibilitou examinar questões de cunho econômico e de caráter social e inferir a influência por esse modo de habitação na cidade capitalista.
\end{abstract}

Palavras-chave: Moradias Verticais, agente Imobiliário, expansão urbana.

\begin{abstract}
Since the beginning of the 2000s, the number of vertical buildings in the urban landscape has been increasing on a global scale. The aim of this article is to analyze the emergence and growth of vertical buildings in the municipality of São João del-Rei (Minas Gerais), through its expansion to the north-northeast direction, to the Colônia do Marçal neighborhood. As specific objectives we detach the analysis of the action of the agents who produce urban space (landowners and real estate developers). In addition, we seek to understand the increase of the demand for this type of housing. For the development of this research they were made bibliographic and data examinations and they were applied evaluation questionnaire to the population residing in the vertical buildings and to real estate agents, which made possible to scrutinize economic and social issues and infer the influence of this type of housing in the city.
\end{abstract}

Keywords: Vertical buildings, real estate agent, urban expansion.

\section{Introdução}

O processo de urbanização no Brasil ocorreu de forma acentuada a partir da década de 1960 (STAMM et al., 2013). Contudo, esse processo não foi homogêneo, tendo como principal lócus a região Sudeste (TOLEDO, 2011). Assim, o processo de urbanização apresenta taxas desiguais para cada região do país relacionada ao seu processo de formação (SANTOS, 2008).

\footnotetext{
${ }^{1}$ Mestrando do Programa de Pós-Graduação em Geografia (PPGEOG) da Universidade Federal de São João delRei.

${ }^{2}$ Licenciada em Geografia pela Universidade Federal de São João del-Rei.

${ }^{3}$ Professor Doutor Associado do Departamento de Geografia da Universidade Federal de São João del-Rei.
} 
O atual processo de urbanização brasileiro se dá de acordo com as novas demandas que o capitalismo financeiro impõe às cidades, perpetuando a sua (re) produção, no início do século XXI (MARICATO, 2008). Ora, tem início a produção de um "novo espaço", no qual o mercado imobiliário se torna cada vez mais rentável e segregador. Desta forma, "a mercadoria-espaço mudou de sentido com a mudança de orientação (prioridade) das aplicações financeiras: da realização do ciclo industrial da mercadoria à produção do imobiliário" (CARLOS, 2015, p.26).

Dessa articulação do capital, em que o valor de "troca" supera o valor de uso do solo (CORRÊA, 1989), resultam contradições:

O capitalismo "criou" a moderna propriedade fundiária, transformou um bem (a terra) que era essencialmente valor de uso em algo com valor de troca. Mas, contrariamente aos produtos do capital que saem da produção industrial como mercadorias que precisam se realizar através do valor de troca, um terreno para adquirir preço ou dar retorno como renda para o proprietário não tem nenhuma necessidade social de ser vendido. Uma mercadoria qualquer pode ser reproduzida, aliás, normalmente é fabricada aos milhares, mas a terra não. Impossível reproduzir algo que não foi fabricado, que pode existir como mercadoria unicamente porque é um lugar com características singulares. Um proprietário detém sempre um monopólio sobre um pedaço de terreno, por menor que seja ele. É isto que torna a propriedade da terra tão "valiosa" para seu possuidor (LAHORGUE, 2002, p.50).

Nesse contexto, as habitações verticais tornam-se atrativas e são rapidamente incorporadas pela classe média das grandes cidades (RAMIRES, 1998). Os promotores imobiliários unem o aproveitamento dos terrenos com a localização privilegiada para extraírem mais lucros com este tipo de empreendimento. Um dos fatores que explica a importância dada para a localização é o fato das regiões periféricas geralmente não terem infraestruturas urbanas suficientes e nem uma gama de serviços como, por exemplo, bancos, escolas, supermercados e o transporte público não ser satisfatório (DUARTE; ELALI, 2011). Assim, a verticalização tende a ocorrer em áreas centrais ou pericentrais. Em algumas cidades, entretanto, a questão da interação sociocultural, está ligada ao status e à insegurança de comprar casas pelo medo da violência (DUARTE; ELALI, 2011), promovendo a verticalização também de bairros mais periféricos. Dessa forma, as áreas periféricas, planejadas para garantir uma idealização de "status", tornam-se atraentes à classe média (CORRÊA, 1989).

A cidade de São João del-Rei (MG), devido às transformações econômicas e socioespaciais ocorridas ao longo do seu processo de formação, apresenta uma nova demanda por moradia nas áreas periféricas, afinal, é no espaço urbano que se realizam as ações do presente e do passado (CORRÊA, 1989).

O centro da cidade de São João del-Rei é tombado por ter um conjunto arquitetônico considerado de importância histórica para o país (TAVARES, 2012). Assim, o tombamento do centro São João del-Rei se insere em um contexto de "ações de preservação dos bens culturais da nação, empreendidas pelo Serviço do Patrimônio Histórico e Artístico Nacional, no bojo do projeto cultural do Estado Novo" (TAVARES, 2012, p.89). Nessa esfera, o município de São João del-Rei, juntamente com outras cidades "históricas" de Minas Gerais, veio a se tornar, no ano de 1938, um "símbolo da nação e tombadas em seu conjunto arquitetônico e urbanístico" (TAVARES, 2012, p.90), diante da implementação do decreto-lei $n^{\circ} 25 / 1937$. 
Com o tombamento do conjunto arquitetônico e urbanístico de São João del-Rei, a cidade começou a presenciar, simultaneamente, a sua expansão nos aspectos industriais, comerciais e principalmente, a expansão de seu perimetro urbano (TAVARES, 2012). Assim, o centro urbano da cidade começou a fragmentar-se gradualmente após o seu tombamento, dando espaço aos pequenos comércios e serviços que ali já estavam instalados ao invés de habitações. O tombamento da área central praticamente inviabiliza um processo de verticalização das habitações, uma vez que há rígidas regras para alteração das edificações e da paisagem. Desse modo, além de ocorrer mais tarde do que em outras cidades brasileiras, o processo de verticalização vai se dar em áreas mais afastadas do centro e que tem regras construtivas mais flexíveis.

Em paralelo a essa nova dinâmica do centro urbano da cidade, o bairro Colônia do Marçal, destaca-se por ser um importante eixo de expansão da cidade, onde foram inaugurados diversos empreendimentos imobiliários, com expressiva valorização, a partir dos anos 2000 (SILVA; TOLEDO, 2019).

O objetivo deste trabalho foi analisar o surgimento e a consolidação das habitações verticais no município de São João del-Rei (MG), através da avaliação de sua reprodução no sentido norte-nordeste da cidade, no bairro Colônia do Marçal. As hipóteses são as de que (1) as moradias verticais vêm criando novos modelos de habitação na cidade, acarretando desigualdades socioespaciais; (2) a atuação dos agentes imobiliários envolvidos neste cenário de expansão da moradia vertical é crucial para a propagação deste arquétipo de habitação; e (3) o preço do solo urbano tem impulsionado a busca por esse tipo de moradia. Como metodologia, foi visitado um empreendimento imobiliário, localizado no próprio bairro e aplicado um questionário junto aos agentes imobiliários a fim de caracterizar e identificar as causas da busca por este tipo de moradia. A luz das leituras e teorias levantadas, analisamos a relação entre sua expansão e a ação dos agentes, assim como as consequências da verticalização no bairro e no município.

\section{A cidade de São João del-Rei e a sua expansão no eixo norte-nordeste}

A cidade de São João del-Rei (Figura 1) fica localizada na Mesorregião do Campo das Vertentes, sudoeste do estado de Minas Gerais, apresenta uma população estimada de 89.653 habitantes e a sua densidade demográfica é de $57,68 \mathrm{hab} / \mathrm{km}^{2}$, de acordo com o último censo do Instituto Brasileiro de Geografia e Estatística (IBGE, 2018). A cidade está formalmente dividida em oito bairros: Bonfim, Centro, Colônia do Marçal, Fábricas, Jardim Central, Matosinhos, Senhor dos Montes e Tijuco, apresentando 95\% da sua população residente na zona urbana (OLIVEIRA; TOLEDO, 2016).

São João del-Rei é uma cidade mineira do século XVIII, com mais de 300 anos de existência e que, em sua reprodução espacial, sempre esteve atrelada às demandas da classe dominante (SANTOS, 2017) e aos interesses do Estado. Assim, o uso do solo e a sua ocupação se deram e se dão de acordo com essas relações, pois o homem necessita ocupar um espaço, "mesmo que o ato em si não seja o de meramente ocupar uma parcela do espaço, tal ato envolve o de produzir o lugar" (CARLOS, 2009, p.45).

No contexto de Minas Gerais, o município ocupa a categoria de cidade de médio porte, com características peculiares e heterogêneas (BATELLA, 2014), intercalando as dualidades que as cidades grandes e pequenas apresentam. As cidades grandes detêm uma posição geoeconômica privilegiada, mas lidam com os problemas que o seu crescimento acarreta; já as cidades pequenas, recebem recursos para basicamente, tentar melhorar a qualidade de vida (COSTA, 2002). 
Figura 1- Localização da cidade de São João del-Rei - Minas Gerais.

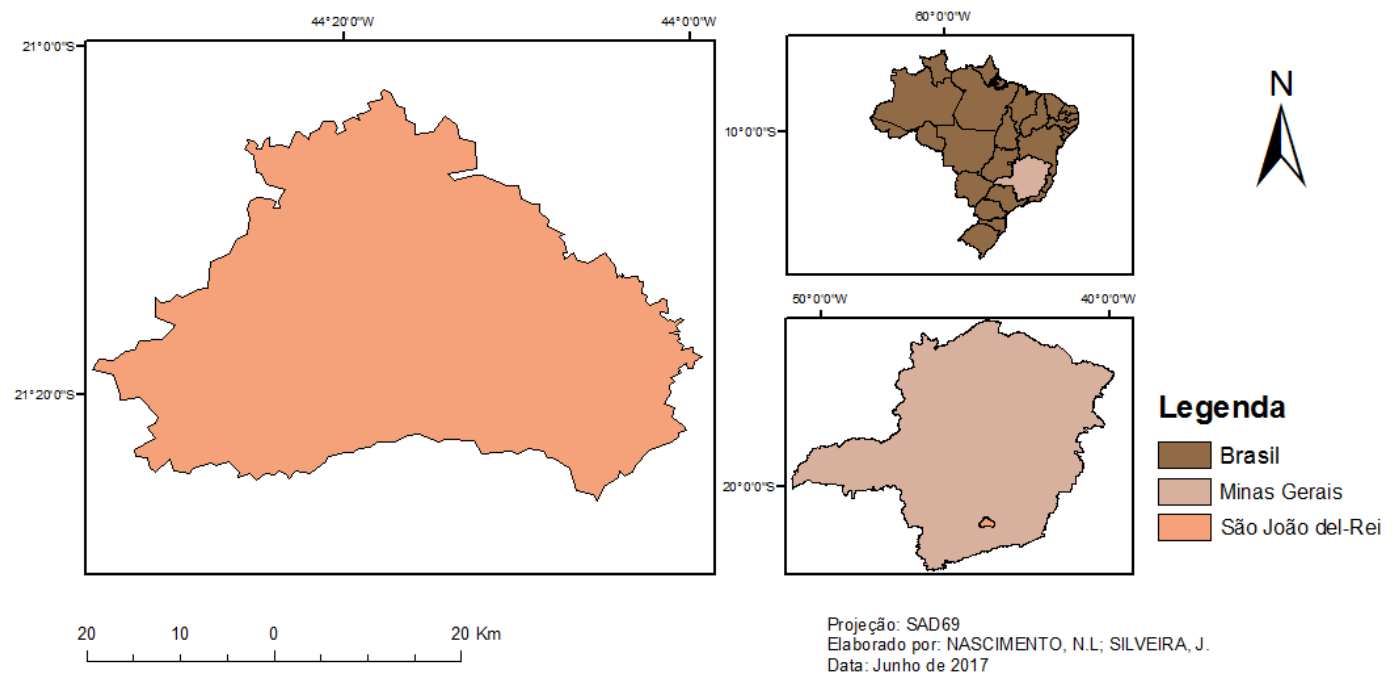

Fonte: Silva (2017).

Essa busca por uma melhor qualidade de vida é observada pelo mercado imobiliário como uma oportunidade lucrativa em que as áreas mais afastadas do centro são apropriadas, tendo como carro chefe de sua campanha de marketing a promessa de elevar a qualidade de vida de parcela específica da população, a classe média (ZACCHI, 2014). Nessa esfera, a cidade de São João del-Rei tem se expandido em todas as direções, principalmente no eixo norte-nordeste (OLIVEIRA, 2017). Este eixo vem recebendo investimentos sistemáticos dos agentes imobiliários (com a construção de edifícios verticais ou condomínios fechados), o que acaba por contribuir para ampliar disparidades urbanas, como a segregação e investimentos em pontos selecionados da cidade. Além disso, estas ações de atração imobiliária são impulsionadas pelo poder público municipal que disponibiliza licenças para que novas áreas e novas formas de habitação sejam edificadas, ofertando o devido suporte estrutural para que elas se tornem atrativa.

De acordo com Maia (2017), é possível perceber que o Estado é marcado por disputas, pois, inserido nas lógicas do capital, tende a favorecer o interesse das classes dominantes. Tal fato potencializa ações e práxis marcadas por contradições e desigualdades. Assim, emerge uma tendência que se repete em que o Estado está em constante alinhamento com os interesses econômicos da classe dominante local e, assim, supre as suas demandas:

O Estado atua com uma lógica territorial própria para manter a hegemonia de determinadas frações de classe e a dominação política, bem como para garantir as condições de reprodução gerais de produção de parte do conjunto social, necessários à sua reprodução (LIMONAD, 2014, p.5).

Logo,

O espaço urbano passa a ser produzido sob a égide do valor de troca que se impõe ao uso social da cidade. Esse processo se realiza apoiado na existência da propriedade privada da riqueza, criando acessos diferenciados dos cidadãos à cidade, a partir da aquisição da moradia (MAIA, 2017, p.21).

Dessa forma, a cidade de São João del-Rei começa a criar em seu espaço urbano, disparidades no que diz respeito à moradia, fortalecendo problemas relacionados ao acesso à moradia e à ocupação da terra (JUNIOR, 1997). Assim, emergem questões ligadas a essa disparidade como, por exemplo, onde deve-se habitar, quem deve habitar, e como deve ser 
habitado. Os agentes imobiliários e os incorporadores de terra passam a atuar em áreas da cidade com maiores potencialidades para a realização de lucro, agregando o olhar financeiro capitalista e fomentando as discrepâncias econômicas e sociais no que diz respeito à moradia (MARICATO, 2003).

\section{O bairro Colônia do Marçal e o mercado imobiliário}

A utilização do solo varia de cidade para cidade, porém, cada uma delas segue uma tendência no que diz respeito à definição de áreas e suas respectivas estruturas (SINGER, 1980). Nessa esfera, o uso do solo urbano vai se definir conforme a sua funcionalidade, ou seja, quais são os locais destinados à moradia, às atividades econômicas, às áreas comerciais e de serviços, às áreas de lazer e aquelas que são reservadas para uma futura expansão (CORRÊAA, 1989).

Historicamente, o bairro Colônia do Marçal foi constituído por imigrantes europeus, sendo em maioria italianos. O intenso fluxo imigratório ocorreu entre o final do século XIX e início do século XX, devido a demanda de mão de obra para suprir a lacuna deixada pela recente libertação da mão de obra escrava e, consequentemente, para atender as correntes de pensamento que aderiam a teorias que pregavam a "superioridade racial europeia e a inferioridade do trabalhador nacional e também ao momento de positivação do conceito de trabalho" (TEIXEIRA, 2011). Logo, devido à necessidade de mão de obra agrícola especializada, e embasado por uma linha de pensamento racista pautada na eugenia, a imigração europeia foi incentivada pelo Estado brasileiro.

Neste contexto histórico, os imigrantes italianos que chegaram a São João del-Rei começaram a se instalar ao longo da cidade, agrupando suas comunidades e desenvolvendo suas práticas agrícolas, principalmente na Várzea do Marçal (COTA; DIÓRIO, 2012), hoje, bairro Colônia do Marçal. Como consequência, a área então ocupada pelos italianos, começa a se expandir, motivando o Estado a doar as terras despovoadas para que as famílias de imigrantes fixassem suas moradias e praticassem suas atividades agrícolas (TEIXEIRA, 2011). Logo:

Os imigrantes ali instalados foram incorporados à sociedade local com o status de empresários ou empreendedores, atuando tanto no setor industrial (tecelagem) quanto no comercial e de serviços, incluindo aí as empresas de construção civil (COTA; DIÓRIO, 2012, p.6).

Logo, o suporte dado ao povo italiano, ou seja, a terra, através do Estado, possibilitou a negociação do espaço no qual novas formas de uso e ocupação foram empregadas. Assim, as terras recebidas passavam a desempenhar várias funções. Era possível dividir, vender, edificar casas ou pontos comerciais nos lotes recebidos. Com o passar do tempo, alguns dos proprietários fundiários começam a se tornar promotores imobiliários, que loteiam, vendem e constroem habitações nessas áreas (CORRÊA, 1989), definindo assim, o seu papel crucial no mercado imobiliário e na expansão urbana do bairro.

Atualmente, a Colônia do Marçal vem sofrendo transformações no que diz respeito a ocupação do solo. A partir de meados dos anos 2000, várias estruturas urbanas foram instaladas no bairro, o que auxiliou um processo de expansão urbana naquela direção (ANDRADE et al., 2014). Como consequência, o mercado imobiliário foi capaz de penetrar e ampliar a sua influência sobre o espaço urbano, oportunizando uma reorganização espacial (RESENDE, 2013). 
Nessa perspectiva, a nova estrutura social do bairro Colônia do Marçal sofreu modificações com a desagregação e venda de terra, apoiada no surgimento de "novos sujeitos, variáveis de valorização e práxis produtivas no território, viabilizando refletir sobre a ação, influência e dinâmica do setor imobiliário na produção dos municípios" (SILVA; TOLEDO, 2019, p.103).

O processo de expansão urbana passa a ocorrer em bairros adjacentes e mais afastados do centro urbano e, com isso, passam a emergir novas centralidades (SINGER, 1980), mesmo que incipientes.

Assim, os domínios econômicos, como a indústria, a agricultura e o comércio reestruturaram-se, reorganizando o bairro (SILVA; TOLEDO, 2019) e criando novas centralidades. Em virtude desse processo, a demanda por solo urbano muda frequentemente, pois:

[...] dependendo, em última análise, do próprio processo de ocupação do espaço pela expansão do tecido urbano, o preço de determinada área deste espaço está sujeito a oscilações violentas, o que torna o mercado imobiliário essencialmente especulativo. Quando um promotor imobiliário resolve agregar determinada área ao espaço urbano, ele visa um preço que pouco ou nada tem a ver com o custo imediato da operação. A "valorização" da gleba ó antecipada em função de mudanças na estrutura urbana que ainda estão por acontecer e, por isso, os especuladores dispõe a esperar certo período, que pode ser bastante longo, até que as condições propícias se tenham realizado (SINGER, 1980, p.79, grifos dos autores).

Assim, o bairro começou a "pluralizar aceleradamente e sem controle, em consequência de uma forte valorização imobiliária" (SILVA; TOLEDO, 2019, p.104), contribuindo para que novas infraestruturas fossem se firmando no bairro, como o caso da verticalização habitacional (RESENDE, 2013).

\section{O crescimento das moradias verticais}

Acompanhando uma tendência mundial, a verticalização das moradias manifesta-se no cenário brasileiro com um caráter de modernidade (RAMIRES, 1998). Essa tendência começa a se firmar primeiro nas grandes cidades, como São Paulo e Rio de Janeiro, já que ambas as cidades brasileiras foram pioneiras no processo de verticalização (DOS SANTOS, 2010), promovendo assim, a transformação do espaço urbano da cidade. Diante dessa perspectiva, assim como os demais processos da urbanização, essa "moda" urbanística, começa se espalhar, "principalmente em grandes e médias cidades brasileiras, e que pode ser entendido como uma das fases do processo de urbanização no Brasil" (DOS SANTOS, 2010, p. 165).

Conforme Negri (2011), pode-se compreender o processo de verticalização como a criação de novos espaços, novos solos, na qual estão sobrepostos, sendo direcionados assim, como um ambiente de moradia ou trabalho, alocados em diversos andares, viabilizando uma abundância populacional, que pode exercer várias funções. No que diz respeito a esse estudo, a verticalização tem o papel de moradia, onde uma pequena porção do solo passa a agrupar e aglomerar a maior quantidade de pessoas no mesmo lugar (CASARIL, 2009). Os prédios então tornam-se elementos substanciais para a mudança na paisagem urbana do bairro (MACHADO; MÉNDES, 2003) e, consequentemente, o setor imobiliário começa a impulsionar sua construção.

Argumentamos aqui, como uma possível justificativa, que um dos motivos que proporcionou a expansão das moradias verticais no bairro Colônia do Marçal, relaciona-se 
com a concepção de modernização (FRESCA, 2002). Assim, conforme Lefebvre (2013, p.127), "o espaço da modernidade tem características precisas: homogeneidade fragmentação - hierarquização". Além disto, como afirmamos anteriormente, o centro histórico da cidade ao ser tombado, justamente na mesma época em que a cidade começava a se expandir, tanto nos aspectos urbanos quanto econômicos, proporcionou que a cidade direcionasse a sua expansão para os bairros adjacentes ao centro, fazendo com que a modernização ocorresse em outras áreas da cidade ${ }^{4}$ (TAVARES, 2012).

Além disso, acompanhado do setor imobiliário, as áreas que antes eram ocupadas por diferentes funções, como por exemplo, criação de animais, pasto, áreas de caráter comercial e residências, começam a se transformar, dando espaço aos edifícios verticais. Esses novos espaços verticalizados passam a ser potencializados para desempenhar diferentes funções, com o objetivo de atender serviços diversos e principalmente, a moradia (GALESI; NETO, 2016). Desta forma então:

A verticalização do espaço urbano, sem sombra de dúvidas, representa uma revolução na forma de construir, afetando a dinâmica de acumulação/reprodução do capital no setor da construção civil e mercado imobiliário (RAMIRES, 1998, p.98).

Em São João del-Rei, pode-se observar a expansão da cidade em direção a diferentes bairros (OLIVEIRA; TOLEDO, 2014) por meio da verticalização direcionada ao uso residencial com três modelos diferentes: o primeiro voltado para os bairros periféricos, adjacentes ao centro, que vão receber a verticalização para a moradia de camadas sociais menos capitalizadas, na qual os investimentos serão fracionados e reduzidos; o segundo, direciona-se para a verticalização ao entorno dos campus universitários da cidade, onde se busca atingir o público universitário (estudantes, técnicos e professores) vindo de outros locais e; o terceiro, direciona-se para os bairros mais afastados do centro, mas que conferem algum "status" e que sofrem fortemente com a especulação e valorização imobiliárias (SILVA; TOLEDO, 2019).

O processo de expansão urbana no sentido da Colônia do Marçal insere-se no terceiro modelo: bairro periférico que sofre com a especulação imobiliária. Esse fenômeno é detectado devido à expansão urbana do bairro, que vem criando modelos e moldes de habitação para atender a população (COTA; DIÓRIO, 2012), acarretando assim, simbologias no espaço urbano (CORRÊA, 1989).

Nessas circunstâncias, como exemplo da especulação imobiliária, o valor de $\mathrm{m}^{2}$ da cidade de São João del-Rei cresceu significativamente, segundo OLIVEIRA (2017, p.45), entre 2005 e 2015 :

o valor do metro quadrado de terreno na cidade de São João del-Rei aumentou a uma proporção de aproximadamente $262,38 \%$, ou seja, enquanto o valor médio do metro quadrado em 2005 era de $\mathrm{R} \$ 90,79$, em 2015 o valor médio de metro quadrado era de $\mathrm{R} \$ 347,16$.

Não diferente da tendência da cidade, o bairro Colônia teve seu aumento de $\mathrm{m}^{2} \mathrm{com}$ variação de preço em torno de $342 \%$, passando de $\mathrm{R} \$ 70,55$ em 2005 (IGP-M) ${ }^{5}$ para R\$ 311,61 em 2015.

\footnotetext{
${ }^{4}$ Como exemplo, podemos citar o bairro Fábricas, que durante o período industrial da cidade, concentrou atividades economicas industriais (textil) afastado do centro histórico de São João del-Rei.

${ }^{5}$ Os valores de 2005 foram corrigidos ano a ano utilizando-se o Indice Geral de Preços (IGPM).
} 
Figura 2 - Bairro Colônia do Marçal como vetor de expansão urbana na cidade de São João del-Rei.
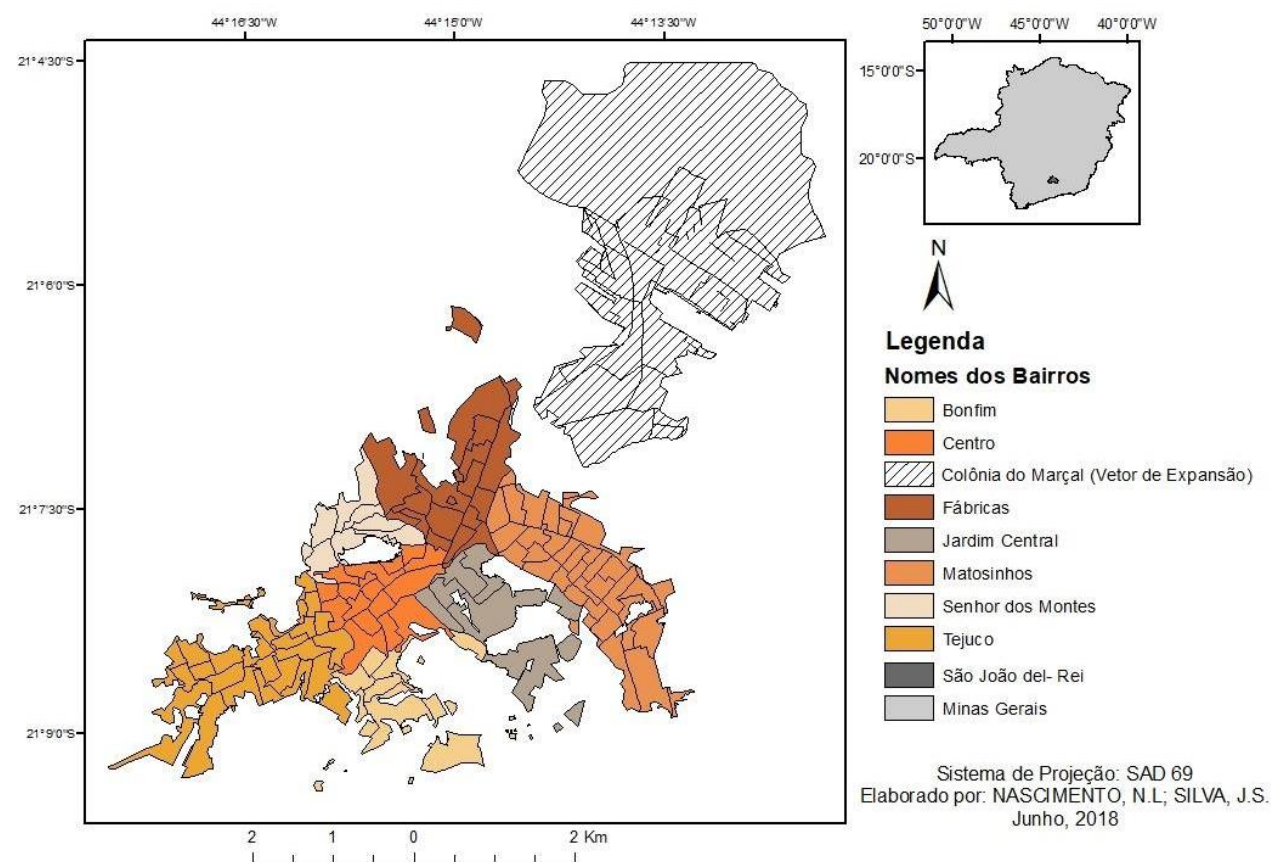

Fonte: Silva (2018)

Atualmente, o bairro Colônia do Marçal, conta com diversos edifícios verticais destinados à habitação (Figura 3). É preciso destacar que, para este estudo, foram selecionadas as estruturas habitacionais de maior porte, ou seja, aquelas em que as obras já estavam acabadas, em fase de finalização ou que já haviam sido ocupadas e apontar a construção que fomentou esse trabalho: Residencial Vila Real de 2017. Dentre os edifícios verticais, foi observado que a maioria se localiza nas adjacências das duas avenidas principais do bairro: Avenida 31 de Março e Avenida Luiz Giarola. A Avenida 31 de Março (BR 383) é a principal, reconhecida como uma das maiores da cidade, onde se observa um significante número de empreendimentos (bares, lojas, padaria, hotéis), e a outra, menos expressiva mas também importante, com um caráter mais residencial (SILVA; TOLEDO, 2019).

Figura 3- Fachada dos edifícios verticais no bairro Colônia do Marçal.

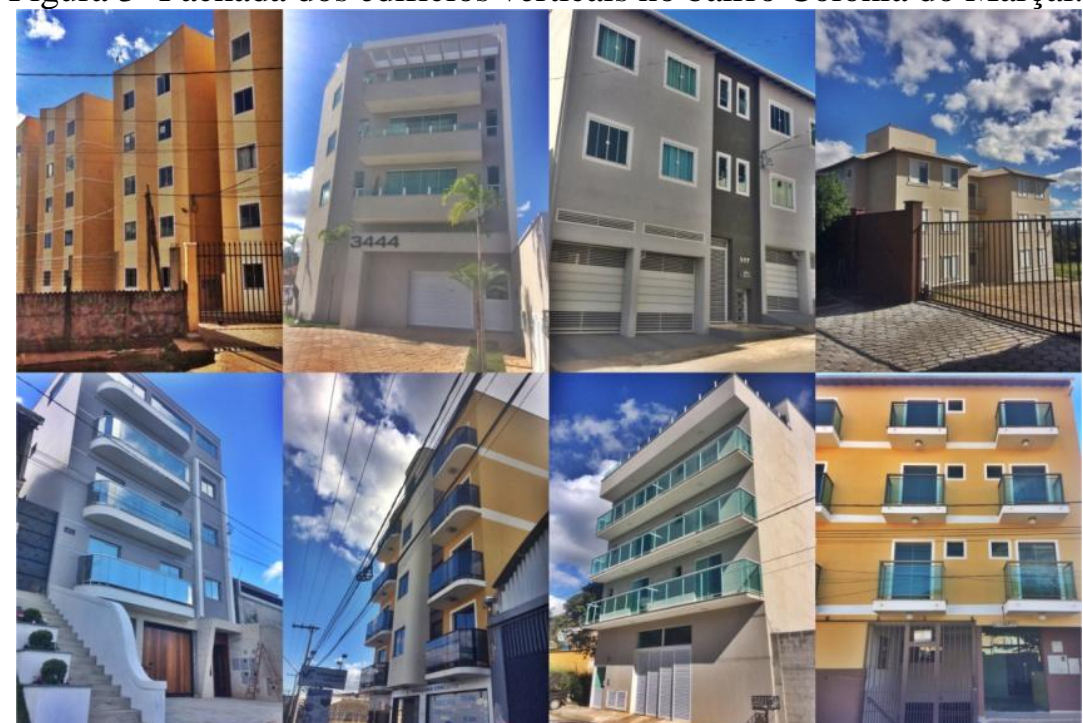

Fonte: Silva (2019). 
Durante esta pesquisa, foram visitados três empreendimentos do ramo imobiliário dentro do próprio bairro ${ }^{6}$, que tinham participação na venda de apartamentos do Residencial Vila Real, a fim de se averiguar alguns aspectos ( $O$ que motivou a elucidação desse tipo de habitação na Colônia? Qual o perfil dos moradores? Ocorreu uma maior procura pelos prédios nos últimos 10 anos?). Além disso, foi realizado entrevista com moradores do Residencial Vila Real ${ }^{7}$, com o objetivo de apurar alguns tópicos ( $O$ que motivou a vinda para a Colônia do Marçal? Por que escolheu a Colônia? Por que não optou por buscar casas?).

No que diz respeito à primeira questão, relacionada aos motivos desse novo modelo de habitação, o corretor de imóveis discorre:

Os motivos que levam a habitação em prédio são: contato com a natureza, morar afastado do caos urbano do centro, e pensar em ter algo próprio (Corretor Imobiliário, 2019).

Nesse contexto, destacamos a fala do entrevistado (1), que afirma:

Me mudei pois o bairro é tranquilo e bem falado. De onde eu vim, estava começando a ficar tumultuado e a Colônia sempre foi um bairro bem visto na cidade. Colocamos a venda nosso outro imóvel (casa) e demos entrada nesse apartamento. É outro mundo morar aqui.

Já para o entrevistado (2) a situação é outra:

Sou morador de São João del-Rei tem anos. Me mudei de Belo Horizonte para cá no começo dos anos 90 e optei por morar perto do centro, pois achava bem localizado e mais acessivel. Com o crescimento da cidade, o bairro que moro se transformou totalmente, fazendo com que comprassemos esse novo apartamento. Apesar do empreendimento se localizar perto de uma longa avenida, é super tranquilo residir aqui.

Ora, segundo o corretor entrevistado ainda explica o motivo dessas construções, como por exemplo, o caso de alocar distintas moradias em uma pequena porção de espaço. Logo, de acordo com Ramires (2002):

Verticalizar significa criar novos solos, sobrepostos, lugares de vida dispostos em andares múltiplos, possibilitando, pois, o abrigo, em local determinado, de maiores contingentes populacionais do que seria possível admitir em habitações horizontais e, por conseguinte valorizar e revalorizar estas áreas urbanas pelo aumento potencial de aproveitamento (MACEDO, 1987 apud RAMIRES, 2002, p.9 grifos dos autores).

Por conseguinte, no que corresponde, ao perfil dos moradores, o corretor imobiliário afirma que:

\footnotetext{
${ }^{6}$ Foram visitadas sete imobiliárias dentro de São João del-Rei, na qual grande parte delas não trabalhavam com empreendimentos no bairro Colônia do Marçal. Dentre elas, apenas duas tinham correlação com o empreendimento analisado.

${ }^{7}$ A coleta de dados dos moradores foi levantada sob uma conversa informal, sem um roteiro pré-estabelecido e definido. Durante duas semanas, o Residencial foi visitado juntamente com um dos corretores imobiliários, com o intuito de coletar as entrevistas.
} 
A classe média, é o publico de maior adesão pela moradia, principalmente o Residencial Vila Real, dado ao exposto que tem parceria com o projeto minha casa minha vida (Corretor Imobiliário, 2019).

O agente imobiliário ainda assegura que ocorre o deslocamento dos indivíduos de outros bairros da cidade, para a Colônia do Marçal, o que potencializa esse tipo de construção para quem busca, principalmente, a casa própria, conforme denota o entrevistado (3), morador do Residencial Vila Real:

Eu me mudei para São João del-Rei recentemente. Meus familiares moram perto do prédio. Estive olhando os poucos terrenos que sobraram nessa área, e os preços estão altos. $O$ gasto que eu teria comprando a terra e construindo, eu adquiri o apartamento praticamente pronto e bem mais barato. Era uma acessibilidade mais fácil e mais em conta (Morador do Residencial Vila Real, 2019).

Nessa perspectiva, "a ideologia da casa própria tem servido como argumento do Estado brasileiro para a implementação de uma política habitacional de mercado no país" (DE MEDEIROS, 2007, p.9). Por fim, no que diz respeito à procura desse tipo de habitação nos últimos anos, o corretor entrevistado evidência:

Os prédios são algo ainda recente, mas, como a Colônia tem se tornado um vetor de expansão, isso tem começado a ocorrer de forma discreta. $O$ tombamento do centro urbano da cidade também é capaz de potencializar isso no bairro, além da expansão dos demais como Matozinhos e Fábricas (Corretor Imobiliário, 2019).

Destaco também, o lugar que o Residencial Vila Real ocupa no bairro Colônia, devido as estruturas físicas que o cercam. Existem pontos comerciais perto, o que potencializa a busca por esse tipo de habitação. Por exemplo, o ponto de ônibus fica 5 minutos do Residencial (Corretor Imobiliário, 2019).

Em sequência, o corretor cita um novo empreendimento na cidade, verticalizado e destinado à moradia, que se insere no bairro Matozinhos, outro vetor de expansão da cidade. Como ele mesmo menciona, "o bairro tem crescido bastante nos últimos anos e com isso, tem ocorrido à busca por novos modelos e moldes de habitação, o que potencializa a sua verticalização e a mudança na paisagem". Por fim, o entrevistado (4), residente no bairro há mais de 15 anos, afirma que:

Apesar de a verticalização chegar bem acelerada na Colônia, se analisamos os últimos 5-8 anos, o bairro ainda mantem um carater residencial $e$ familiar. Bairros na cidade como: Matozinhos, Fábricas e Bonfim tem dado espaço para ambientes comerciais e moradias universitárias, coisa que na Colônia ainda não ocorre com frequência. Temos no bairro alguns pontos comerciais, mas pouco, quando comparado com outros bairros. A Colônia ainda tem muito a se expandir e crescer e a verticalização será o processo para isso ocorrer. 


\section{Para concluir}

Em São João del-Rei, percebe-se que tem ocorrido novas formas de habitação, como a verticalização no bairro Colônia do Marçal, oriundo de diversos fatores, como a busca de um contato com a natureza e afastamento do centro urbano. Este fato potencializa uma a valorização de distintas áreas, muitas vezes afastadas do centro.

As mudanças no espaço urbano são resultado também da atuação mais intensiva dos agentes imobiliários e dos proprietários fundiários, ocasionando assim, a reestruturação do espaço conforme o capital e os seus interesses (CORRÊA, 1989). No bairro Colônia do Marçal, o processo de verticalização ocorre ligeiramente e transforma-se de acordo com as ações do capital. Assim, através das ações dos agentes imobiliários e dos proprietários fundiários, tem sido possível valorizar mais ou menos um bairro dentro do município, e consequentemente, promover a segregação socioespacial no espaço urbano.

A construção de edifícios verticais em São João del-Rei ocorre principalmente em bairros adjacentes ou afastados do centro devido à vários fatores: o primeiro é tombamento do centro histórico e a impossibilidade de verticalização, acarretando a expansão para outros bairros; o segundo relaciona-se com a expansão dos campus da universidade, porque a demanda por habitação cresceu, fazendo com que os proprietários e incorporadores de terra acelerassem o processo de verticalização em bairros próximos aos campi e, por fim, é preciso mencionar "o sonho da casa própria", fincado no ideário nacional.

Assim, o espaço urbano em São João del-Rei reforça sua histórica fragmentação, reconfigurando um contexto que combina crescimento populacional, expansão do mercado imobiliário, aumento vertiginoso do preço do solo urbano e políticas habitacionais que privilegiam mais os capitais imobiliários do que as necessidades de moradia. Assim, o processo de urbanização vertical embasado em diversas justificativas e simbologias, tende a proporcionar o surgimento de novos moldes de habitação, fundamentados nas lógicas do mercado imobiliário e dos seus sujeitos. Por fim, a verticalização que surge e se consolida no bairro Colônia do Marçal, principalmente destinada à moradia, não é uma realidade independente, ou mesmo, um fato isolado no contexto do espaço urbano das cidades, mas, é uma versão residencial de uma nova (re)configuração e reestruturação do espaço, na esfera das cidades contemporâneas, da modernidade e da globalização que tem evidenciado e propiciado novas formas e novos moldes de habitação.

\section{Referências}

ANDRADE, R. B; TOLEDO, M. R; OLIVEIRA, J. S; BARBOSA, A. R. Análise crítica do atual processo de expansão urbana em São João del-Rei (MG) a partir do bairro Colônia do Marçal. In: SIMPÓSIO MINEIRO DE GEOGRAFIA, 1., 2014, Alfenas. Anais... Alfenas: UNIFAL, 2014. p. 994-1008.

BATELLA, W. Assimetrias das relações entre verticalidades e horizontalidades no estudo de cidades médias: problematizações a partir da cidade de Teófilo Otoni - MG. GEOUECE, Fortaleza, v. 3, n. 4, p. 238-267, 2014.

CARLOS, A. F. A reprodução do espaço urbano como momento da acumulação capitalista. Crise Urbana, Ed. Contexto. São Paulo: USP, 2015.

. A Cidade. Contexto: São Paulo, 2009. 
CASARIL, C. C. A expansão físico-territorial da cidade de Londrina e seu processo de verticalização: 1950-2000. Geografia (Londrina), v. 18, n. 1, p. 65-94, 2009.

CORRÊA, R. L. O espaço urbano. São Paulo: Ática, 1989.

COSTA, E. M. Cidades Médias. Contributos para a sua definição. Finisterra, v. 37, n. 74, p. 101-128, 2002.

COTA, D. A.; DIÓRIO, A. C. D. Crescimento urbano na "pequeno-média” São João Del Rei, MG: notas preliminares de uma pesquisa. In: SEMINARIO INTERNACIONAL RED IBEROAMERICANA DE INVESTIGADORES SOBRE GLOBALIZACIÓN Y TERRITÓRIO, 12., 2012, Belo Horizonte. Anais... Belo Horizonte: RII, 2012. p. 1-16.

DE MEDEIROS, S. R. F. Q. A casa própria: sonho ou realidade? Um olhar sobre os conjuntos habitacionais em Natal. 2007. Dissertação de Mestrado. Universidade Federal do Rio Grande do Norte, 2007.

DOS SANTOS, C. P. Sobre a Produção do Espaço Urbano e o Processo de Verticalização no Brasil: algumas considerações. Caderno Prudentino de Geografia, n.32, vol.1, p.155-175, 2010.

DUARTE, M. J.; ELALI, G. A. Valor de troca, valor de uso: alguns subsídios para (re)pensar o projeto de condomínios verticais. IN: II Simpósio Brasileiro de Qualidade Do Projeto o Ambiente Construído X Workshop Brasileiro De Gestão do Processo De Projeto Na Construção De Edifícios. Rio de Janeiro. Anais... Rio de Janeiro: PROARQ/FAU/UFRJ e PPG-IAU USP, p.823-833, 2011.

FRESCA, T. M. Mudanças recentes na expansão físico-territorial de Londrina. Geografia (Londrina), v.11, n.2, p. 251-274, 2002.

GALESI, R.; NETO, Candido M. C. Modernismo e Urbanidade: os pioneiros da moradia vertical em São Paulo (2016). Disponível em: < http://docomomo.org.br/wpcontent/uploads/2016/01/Rene-Galesi-Candido-Malta-Campos-Neto.pdf>. Acesso em: 05 mar. 2019.

IBGE. Cidades. Disponível em: <https://cidades.ibge.gov.br/brasil/mg/sao-joao-delrei/panorama> . Acesso em: 02 abr. 2019.

JÚNIOR, N.S. O Direito à Moradia Como Responsabilidade do Estado Brasileiro. Cadernos de Pesquisa, n.7, p. 65-80, 1997. Disponível em:<http://polis.org.br/wp content/uploads/o_direito_a_moradia.pdf>. Acesso em: 14 abr. 2019.

LAHORGUE, M. L. Cidade: obra e produto. Geosul, Florianópolis, v.17, n.33, p 45-60, 2002

LEFEBVRE, H. Prefácio: a produção do espaço. Estudos Avançados, v.27, n.79, p.123-132, 2013.

LIMONAD, E. Estado, espaço e escala no Brasil, subsídios para a reflexão. Scripta Nova. Revista Electrónica de Geografía y Ciencias Sociales, v. 18, p.1-19, 2014. 
MACHADO, J. R.; MÉNDES, C. M. O processo de verticalização do centro de Maringá-PR, Brasil. Investigaciones Geográficas, n. 52, p. 53-71, 2003.

MAIA, L. M. de. Habitação de interesse social e a produção do espaço urbano em São João del-Rei/MG entre os anos 2006-2016. 2017. Dissertação (Mestrado em Geografia) Universidade Federal de São João Del-Rei, São João Del Rei, 2017.

MARICATO, E. Globalização e política urbana Na periferia do capitalismo. Revista Territórios, v.18, n.19, p. 183-205, 2008.

151-166, 2003. Metrópole, legislação e desigualdade. Estudos avançados, v. 17, n. 48, p.

NEGRI, S. M. Incorporação e exploração: condomínios horizontais e verticais como forma de segregação sócio-espacial urbana em Rondonópolis-MT. Boletim de Geografia, v. 29, n. 1, p. 47-65, 2011.

OLIVEIRA, J. T. Educação, expansão das universidades federais e o processo de valorização do espaço urbano em São João del-Rei (MG), 2017. Dissertação (Mestrado em Geografia) - Universidade Federal de São João Del-Rei, São João Del Rei, 2017.

OLIVEIRA, J. T.; TOLEDO, M. R. A valorização imobiliária em São João Del-Rei: transformações urbanas. In: ENCONTRO NACIONAL DE GEÓGRAFOS: A CONSTRUÇÃO DO BRASIL: GEOGRAFIA, AÇÃO POLÍTICA E DEMOCRACIA, 18., 2016, São Luís. Anais... São Luís: UFMA, 2016. p. 1-10.

RAMIRES, J. C. de. L. O Processo de Verticalização das Cidades Brasileiras. Boletim de Geografia, n.1, v.16, p.97-106, 1998.

RAMIRES, J. C. de. L.; GOMES, E. R. Verticalização Litorânea: Uma Análise Preliminar. Geografares. Vitória, n. 3, p. 91-107, 2002.

RESENDE, U. P. Especulação imobiliária e verticalização: um estudo a partir do Parque Cascavel em Goiânia. Geografia (Londrina), v. 22, n. 2, p. 79-102, 2013.

SANTOS, B. H. A formação socioespacial de São João Del Rei/MG e o processo de regionalização do campo das vertentes. Dissertação (Mestrado em Geografia) Universidade Federal de São João Del Rei. São João Del Rei, 2017.

SANTOS, M. A Natureza do Espaço: técnica e tempo, razão e emoção. $4^{\mathrm{a}}$ Ed. Editora Universidade de São Paulo. São Paulo, 2008.

SILVA, J. S.; TOLEDO, M. R. A expansão urbana, o mercado imobiliário e a proliferação dos enclaves residências horizontais no bairro Colônia do Marçal, em São João del-Rei (MG). Geografia (Londrina), v. 28, n. 1, p. 97-115, 2019.

SILVA, K. O. Condomínios fechados, residências secundárias e o uso do espaço público pelo capital imobiliário. Revista Acadêmica Observatório de Inovação do Turismo, Rio de Janeiro, v. 4, n. 1, p. 1-15, 2009.

SINGER, P. O uso do solo urbano na economia capitalista. Boletim Paulista de Geografia, n.57, p.77-92, 1980. 
STAMM, C.; STADUTO, J. A. R.; DE LIMA, J. F.; WADI, Y. M. A população urbana e a difusão das cidades de porte médio no Brasil. Interações (Campo Grande), v. 14, n. 2, p.251-265, 2013.

TAVARES, Denis Pereira. O tombamento do conjunto arquitetônico e urbanístico de São João del-Rei: negociação e conflito entre projetos de apropriação e uso do patrimônio cultural (1938 - 1967). 2012. Dissertação (Mestrado em História) - FFCH Universidade Federal de Minas Gerais, Belo Horizonte.

TEIXEIRA, M. E. Ser italiano em São João del Rei (1888-1914). 2011. Tese (Mestrado em História) - Universidade Federal de Juiz de Fora, Juiz de Fora, 2011.

TOLEDO, E. F. T. São Paulo, Rio de Janeiro e Belo Horizonte: A manutenção da Concentração Socioeconômica Nas Metrópoles da Região Sudeste do Brasil. Revista Geográfica da América Central, v.2, p-1-16, 2011.

ZACCHI, R. C. O espaço urbano da cidade capitalista: um estudo sobre o processo de verticalização da área central da cidade de Viçosa (MG) (1970-2007). Brazilian Geographical Journal: Geosciences and Humanities research medium, Ituiutaba, v. 5, n. 2, p. 352-370, 2014. 